\title{
Vivência de estudantes universitários em tempos de pandemia do Covid-19
}

\section{Experience of university students in Covid-19 pandemic times}

\author{
${ }^{1}$ Renata Martins da Silva Pereira renataenfprofessora@gmail.com \\ 2 Flávia de Souza Selvati \\ ${ }^{2}$ Karina de Souza Ramos \\ ${ }^{2}$ Lohany Gomes Ferreira Teixeira \\ 2 Mariana Vieira da Conceição
}

\section{RESUMO}

Este estudo tem como objetivo levantar e discutir as facilidades e dificuldades apontadas por estudantes de um Centro Universitário frente as mudanças do modo de ensino aprendizagem em sua formação acadêmica, durante o isolamento social proposto pela pandemia de COVID-19. Trata-se de um estudo descritivo, quanti-qualitativo desenvolvido com 159 estudantes da área de saúde. 52\% dos estudantes somente estudam e 88\% possuem computador em casa. Os pontos positivos em relação ao ensino remoto foram flexibilidade de horário para estudar (66\%), seguida da autonomia no processo de aprendizado (34,6\%) e informatização das atividades (30\%). O ponto negativo mais apontado pelos estudantes foi excesso de atividades acadêmicas (71\%). Os demais pontos negativos foram as interferências externas (55,3\%); conexão à internet (48,4\%); ter de atender aos prazos de entrega das atividades (42,7\%); difícil adaptação às tecnologias (16,9\%); ambiente inadequado para os estudos (28,9\%); e outros foi considerado por (11,3\%) participantes. Conclui-se que os estudantes passaram pelo período de adaptação às aulas remotas tendo diferentes experiências e que puderam apontar tantos pontos positivos, como negativos deste novo processo. Torna-se necessário investir em estratégias para minimizar os pontos negativos modificáveis, e propiciar experiências assertivas para os estudantes em formação.

Palavras-chave: Ensino superior. Tecnologia educacional. Educação em enfermagem. COVID-19.

\section{ABSTRACT}

This study aims to raise and discuss the facilities and difficulties pointed out by students at a University Center in the face of changes in the way of teaching and learning in their academic formation, during the social isolation proposed by the pandemic of COVID-19. This is a descriptive, quantitative and qualitative study developed with 159 students in the health field. 52\% of students only study and 88\% have a computer at home. The positive points in relation to remote teaching were flexibility of time to study (66\%), followed by autonomy in the learning process (34.6\%) and computerization of activities (30\%). The negative point most pointed out by the students was excessive academic activities (71\%). The other negative points were external interferences (55.3\%); internet connection (48.4\%); having to meet the deadlines for the delivery of activities (42.7\%); difficult adaptation to technologies (16.9\%); inadequate environment for studies (28.9\%); and others were considered by (11.3\%) participants. It is concluded that the students went through the period of adaptation to remote classes having different experiences and that they were able to point out so many positive and negative points of this new process. It is necessary to invest in strategies to minimize the modifiable negative points, and provide assertive experiences for students in training.

Keywords: Higher education. Educational technology. Nursing education. COVID-19.

1 Centro Universitário de Volta Redonda - UniFOA. Universidade do Estado do Rio de Janeiro - UERJ.

2 Centro Universitário de Volta Redonda (UniFOA). 


\section{INTRODUÇÃO}

Em 11 de março de 2020, a Organização Mundial da Saúde decretou status de pandemia para a doença pelo novo coronavírus - a COVID-19. Nesta pandemia medidas não farmacológicas foram instauradas por estados e municípios brasileiros para reduzir a transmissibilidade do vírus na comunidade e, portanto, retardar a progressão da epidemia. Essas ações tem o potencial de reduzir o impacto para os serviços de saúde, por reduzir o pico epidêmico. Em estudos de modelagem matemática estima-se que, uma redução de cerca de $50 \%$ dos contatos entre as pessoas teria impacto significativo no número total de casos confirmados de COVID-19 (BRASIL, 2020a; BRASIL, 2010b).

E devido aos problemas de saúde pública enfrentados por conta do novo coronavírus o Ministério da Educação lança a Portaria n ${ }^{\circ} 343$ de 17 de março de 2020, autorizando, em caráter excepcional, a substituição das disciplinas presenciais, em andamento, por aulas que utilizem meios e tecnologias de informação e comunicação, sendo as disciplinas essencialmente teóricas. Desta forma as escolas e Instituições de Ensino Superior (IES) do interior do estado do Rio de Janeiro optaram por continuidade das atividades acadêmicas de forma remota, por meio de tecnologias da informação e comunicação (TIC). (BRASIL, 2020c)

Embora o ambiente educacional seja um local importante para disseminar conhecimentos e informações, também é um local fértil para difusão da doença, visto que esta possui alta infectividade, por isso a necessidade de desenvolver estratégias de ensino não presenciais. O que suscita discussões sobre o ensino não presencial e o uso de tecnologias de informação para trabalhar os conteúdos dos cursos superiores durante a pandemia de COVID-19, assim algumas instituições públicas não fizeram mudanças em sua forma de ensino, mas a maioria das IES privadas encontraram formas de manter a continuidade dos cursos durante este período de distanciamento social.

Estudantes do ensino superior vivenciam essas mudanças de forma diferenciada, pois embora, em sua maioria, sejam jovens já inseridos no mundo tecnológico e com uso amplo da Internet, existem aqueles que possuem vulnerabilidades frente ao ensino remoto, por falta de hardware/ferramentas tecnológicas, ou não tendo acesso amplo e contínuo a internet compatível com as necessidades do ensino remoto.

No estudo ora desenvolvido não se trata de investigar práticas de ensino a distância (EAD) e sim o ensino não presencial por meio de mídias digitais e interação remota, estruturadas em modelo de ensino-aprendizagem que utilizam TIC, usufruindo ainda de todos os serviços já existentes na IES. Essa diferenciação torna-se necessária, pois no EAD o aluno pode interagir com tutores/professores, pelo trabalho de administração de fluxos de comunicação exercido por uma organização responsável pelo curso e suporte facilitador dessa interação. Já a aula remota, que vem sendo adotada por diversas IES autorizadas pelo Ministério da Educação, permitem interação virtual dos alunos e docentes, onde os estudantes vivenciam a experiência digital junto com professor com transmissão ao vivo, e nos horários em que aconteciam as aulas presenciais (SILVA, 2016).

Vale ressaltar que o Conselho Nacional de Saúde, não recomenda o ensino dos cursos da área da saúde, ministrado totalmente na modalidade EAD, preocupados com a qualidade da formação e os riscos que podem trazer a sociedade pela falta de interação entre docentes/discentes/usuários durante o desenvolvimento de competências próprias de cada curso superior (CNS, 2020).

O desenvolvimento deste estudo parte da experiência dos autores durante as medidas de distanciamento social, com o uso de dispositivos tecnológicos e metodologias educacionais voltadas para o ensino remoto, em um Centro Universitário do interior do estado do Rio de Janeiro. Onde ficou estabelecida a prática do ensino de forma remota, por meio de acesso às ferramentas tecnológicas que permitiam contato direto entre estudantes e professores, como: plataforma de Blackboard, repositório de material didático e ferramenta Office 365, em especial o Microsoft Teams. 
A problematização está em conhecer como os acadêmicos de um Centro Universitário do interior do estado do Rio de Janeiro estão vivenciando ou vivenciaram essa nova experiência de ensino por meio de tecnologias da informação e comunicação?

Este estudo tem como objetivo levantar e discutir as facilidades e dificuldades apontadas por estudantes de um Centro Universitário frente as mudanças do modo de ensino aprendizagem em sua formação acadêmica, durante o isolamento social provocado pela pandemia de COVID-19.

\section{METODOLOGIA}

O estudo teve uma abordagem quanti-qualitativa e trata-se de uma pesquisa explicativa e descritiva, realizada em um Centro Universitário, na cidade de Volta Redonda-RJ.

O Centro Universitário emitiu uma nota oficial informando sobre a necessidade de implantação de educação remota no período de isolamento social a iniciar no dia 30 de março de 2020, afim de preservar a integridade e a vida dos alunos, professores e funcionários pertencentes a grupos de risco, bem como minimizar os impactos no âmbito da saúde pública.

A amostra foi definida por meio de conveniência, composta por 159 estudantes do ensino superior, e como critérios de inclusão houve a participação de estudantes maiores de 18 anos, com acesso à Internet e devidamente matriculados do primeiro ao último ano dos cursos da área de saúde: Educação Física, Enfermagem, Medicina e Nutrição.

Foram excluídos graduandos menores de 18 anos e matriculados em cursos da IES das áreas de exatas e humanas. Justifica-se essa exclusão pois acredita-se que os graduandos desses cursos já tenham maior aproximação e prática de utilização de redes de computadores em sua grade e considera-se que esse fato diminuiria a dificuldade para adaptação ao ensino remoto.

O instrumento de coleta de dados foi um formulário criado por meio da plataforma Microsoft forms, com perguntas sobre a experiência de acadêmicos sobre seu ensino-aprendizagem via instrumentos de tecnologia de informação e comunicação durante o distanciamento social advindo da pandemia de COVID-19. Cada participante teve acesso a plataforma uma única vez e nenhuma informação a respeito do login ou dados pessoais foi divulgada, seguindo em anonimato.

A tabulação e análise dos dados quantitativos foi gerada na plataforma Microsoft forms e analisadas por intermédio do programa Microsoft Excel. A pergunta aberta foi analisada por análise temática e formação de categorias.

O estudo foi aprovado no Comitê de Ética em Pesquisa com Seres Humanos sob o nº do parecer 4.078.043, conforme resolução 466/2012 do Conselho Nacional de Saúde-CNS, que regulamenta os aspectos legais para Pesquisas com Seres Humanos.

\section{RESULTADOS E DISCUSSÃO}

Participaram da pesquisa, 159 estudantes, sendo 65 (41\%) discentes do curso de Enfermagem, 38 (24\%) da Nutrição, 32 (20\%) da Medicina e 24 (15\%) da Educação Física.

A idade dos estudantes, variou entre 18 e 59 anos, sendo a média de 23. Que encontrou semelhança ao estudo de Luna et al (2017), que contou com estudantes da faixa etária de 18 a 40 anos, sendo a média de 22,8. 
Quanto à renda familiar, a mesma variou entre meio salário mínimo e treze salários mínimos, sendo que a maioria dos estudantes 59 (37\%), apresentava uma renda familiar de 938 até 2.811 reais.

Quanto ao período em que os estudantes estavam cursando, quando participaram da pesquisa, 38 alunos (23,8\%) estavam no $1^{\circ}$ ou $2^{\circ}$ período equivalente ao $1^{\circ}$ ano nos cursos anuais, 23 alunos (14\%) no $3^{\circ}$ ou $4^{\circ}$ período ou $2^{\circ}$ ano, 37 alunos (23,2\%) no $5^{\circ}$ ou $6^{\circ}$ período ou $3^{\circ}$ ano, 51 alunos (32\%) no $7^{\circ}$ ou $8^{\circ}$ período ou $4^{\circ}$ ano, 9 alunos (5\%) no $9^{\circ}$ ou $10^{\circ}$ período e 1 aluno $(0,6 \%)$ no $11^{\circ}$ ou $12^{\circ}$ período. A maioria dos estudantes já estava em uma fase mais adiantada do curso, podendo comparar as atividades presenciais e remotas.

A maioria 82 (52\%) dos estudantes somente estudam e 77 (48\%) trabalham e estudam. Percebe-se um resultado bem próximo se comparado ao artigo de Luna et al (2017), onde tiveram uma média de (63,49\%) contra (52,77\%) do grupo que apenas estudavam. Concluíram nesse artigo que os estudantes que trabalhavam e estudavam obtiveram melhores índices de qualidade de vida no domínio social. Essas informações são relevantes para entender o contexto de vida que o aluno se insere.

Em relação a possuir computador em casa, 140 (88\%) estudantes contam com este apoio tecnológico, entretanto, 19 (12\%) estudantes não possuem este recurso para auxiliar nos estudos. Portanto, é indispensável conhecer as condições dos estudantes, acerca das tecnologias necessárias para o ensino/aprendizagem remotos, e buscar alternativas para substituição de tais tecnologias a fim de evitar prejuízos para um aprendizado inclusivo e universal. (SANTOS JUNIOR e MONTEIRO, 2020).

Se comparado ao artigo de Barbosa, Viegas e Batista (2020), a maior parcela dos estudantes também possuía aparato tecnológico necessário para assistirem às aulas. Destaca-se que embora o número de pessoas sem computador apresenta-se pequeno, muitos não possuem recursos para acompanhar as aulas, e ainda apontaram que nenhuma ação foi realizada para que o discente não se sentisse excluído. Percebe-se, então, a importância de pesquisas que busquem conhecer o perfil dos estudantes, dando subsídio para as IES apresentarem estratégias para sanar tais problemas.

O quadro 1 apresenta itens referentes a satisfação dos estudantes e condições para o desenvolvimento de atividades remotas.

Uma parcela dos estudantes 57 (35,9\%) refere que consegue gerenciar seu tempo para os estudos de forma regular. Já em relação ao sinal de Internet para uso nos estudos, 89 (56\%), ou se, mais da metade dos participantes julga-o como bom. E a adaptação ao ensino remoto foi julgada entre boa e regular pelo mesmo número de estudantes, 55 (34,6\%). 
Quadro 1- Grau de satisfação dos estudantes de uma IES em relação ensino remoto. Volta Redonda/RJ, 2020.

\begin{tabular}{|c|c|c|c|c|}
\hline Questionamentos & $\begin{array}{l}\text { Ótimo } \\
\text { n (\%) }\end{array}$ & $\begin{array}{l}\text { Bom } \\
\text { n (\%) }\end{array}$ & $\begin{array}{c}\text { Regular } \\
\text { n (\%) }\end{array}$ & $\begin{array}{l}\text { Ruim } \\
\text { n (\%) }\end{array}$ \\
\hline $\begin{array}{l}\text { Como você classifica o gerenciamento de seu tempo para se } \\
\text { dedicar aos estudos durante o isolamento social? }\end{array}$ & $20(12,6)$ & $48(30,2)$ & $57(35,9)$ & $34(21,3)$ \\
\hline Como você julga seu sinal de internet? & $27(17)$ & $89(56)$ & $36(22,6)$ & $7(4,4)$ \\
\hline $\begin{array}{l}\text { Como você julga sua adaptação a educação remota através de } \\
\text { aulas online e atividades independentes a distância nesse período } \\
\text { de isolamento social? }\end{array}$ & $16(10,1)$ & $55(34,6)$ & $55(34,6)$ & $33(20,7)$ \\
\hline
\end{tabular}

Fonte: Dados da pesquisa, 2020.

Estudo realizado por Barbosa, Viegas e Batista (2020), destacaram através de um relato de experiência de professores sobre aulas remotas, que houve menor participação dos alunos se comparado às aulas presenciais. Assim como no presente estudo, os estudantes julgam que o gerenciamento do tempo, apesar do distanciamento social, ficou prejudicado durante a pandemia. Esse fato remete a necessidade de treinamentos sobre organização dos estudos, priorização de atividades e autoconhecimento por parte dos estudantes sobre seu papel no processo de ensino/aprendizagem.

Barbosa, Viegas e Batista (2020), obtiveram em seu estudo um resultado diferente em relação ao acesso à internet, onde 33\% dos referiu que a internet que possuem não atende à demanda das aulas, trazendo prejuízos ao aprendizado e desânimo em participar de atividades remotas.

A adaptação dos estudantes às aulas remotas torna-se relevante tema de discussão em tempos de pandemia, devendo as IES atentarem para esses números, pois uma boa adaptação do aluno reflete diretamente no aprendizado. Faz-se necessário uma comunicação aberta para tentar solucionar divergências, e considerar que toda transição requer adaptação e, por vezes, uns se adaptam melhor que outros. Por isso, há a necessidade de cooperação e aprendizado coletivo para superar eventuais limitações (SANTOS JUNIOR \& MONTEIRO, 2020).

Em relação aos pontos positivos apontados pelos estudantes, em relação ao ensino remoto, observou-se que 105 (66\%) dos 159 estudantes apontaram a flexibilidade de horário para estudar, seguida da autonomia no processo de aprendizado 55 (34,6\%). E ainda, 48 (30\%) dos estudantes, apontaram a informatização das atividades e organização dos materiais/ conteúdos, como pontos positivos do ensino remoto.

Estudo realizado em Caruaru/PE também destacou como pontos positivos, que a disciplina do semipresencial estimulou a construção do conhecimento onde o discente deve tomar cuidado com a qualidade dos materiais escolhidos para estudo, tendo flexibilidade e autonomia para desenvolver seu aprendizado (SILVA et al, 2020).

O ponto negativo mais apontado pelos estudantes foi excesso de atividades acadêmicas com 113 (71\%).

Desta forma, um ponto importante a ser discutido é o preparo dos docentes e os modelos avaliativos aplicados, pois o ensino remoto exige uma mudança de postura do professor, que precisa atuar de maneira dinâmica que reforce a participação dos alunos, e muitas vezes, não se tem ainda, o aparato necessário para avaliar de forma mais objetiva, fazendo assim, o uso de trabalhos em grupo, resenhas, análises de materiais, etc. que geram maiores demandas aos estudantes para cumprir os prazos e fazer as entregas de materiais produzidos (FERNANDES et al, 2018; SILVA et al, 2020). . 
Os demais pontos negativos foram as interferências externas 88 (55,3\%); conexão à internet 77 (48,4\%); 68 (42,7\%) ter de atender aos prazos de entrega das atividades; 27 (16,9\%) difícil adaptação às tecnologias; 46 (28,9\%) ambiente inadequado para os estudos; e outros foi considerado por $18(11,3 \%)$ participantes.

Em contrapartida, Fernandes et al (2018) encontrou em seu estudo que os principais pontos negativos são superficialidade, isolamento social, distância entre aluno e professor e dificuldade de identificação das necessidades dos alunos pelos professores. Questões em sua maioria ligadas a interação próprias do ensinar/aprender entre estudantes e professores e que, com a necessidade de isolamento social, ficaram mais explicitas em tempos de pandemia.

É preciso deixar claro que quem ensina e quem aprende não precisam estar necessariamente presentes no mesmo espaço, mas deve haver, sim, no caso do ensino remoto, a busca de metodologias para o espaço virtual que permitam esse diálogo entre mediador e aluno evitando, assim, um caráter instrucionista, e sim formativo (CAVALCANTI et al, 2017).

O momento de aprendizagem depende da interação entre professores, estudantes, famílias, escolas, sociedade organizada, instituições de ensino superior e poder público, na busca por estratégias sustentáveis e inclusivas a todos, que assegurem qualidade técnica e promova a formação profissional de qualidade e não provoque possíveis reveses justificados por um contexto completamente atípico no campo da educação superior em saúde (COSTA et al, 2020).

Após análise das respostas abertas emergiram duas categorias que se referem as experiências dos estudantes em relação às aulas remotas: Adaptação positiva ao ensino remoto e Influência do ambiente na experiência dos estudantes com o ensino remoto.

\section{1 Adaptação positiva ao ensino remoto}

Assim como toda a sociedade, os estudantes, em sua maioria jovens, demonstraram capacidade de adaptação às mudanças ocorridas, a partir das mudanças, no formato de ensino. Com o passar do tempo e a exposição à nova experiência de aprendizado, os estudantes apresentaram uma adaptação positiva e capacidade em lidar com o novo.

\footnotetext{
"No primeiro bimestre acabei passando por dificuldades por conta da quantidade de trabalhos a serem entregues para compor a nota, já no segundo bimestre estipularam uma menor quantidade, sendo assim mais fácil de acompanhar [...].”
}

"No começo estava sendo de difícil adaptação mas com o tempo fui me acostumando e dando chance a uma nova experiência."

Competências como, planejamento das ações e organização do trabalho, também ficaram evidentes, e demonstram que o processo de aprender com autonomia pode facilitar o desenvolvimento profissional e a aquisição de novas habilidades.

"Estou descobrindo algumas habilidades de planejamento e organização de estudos e graças aos recursos que tenho consigo me concentrar e criar uma rotina de estudos adequada."

“[...] tem sido uma boa experiência e que permite aprender de outras maneiras mais atuais e não somente pelo método tradicional em sala de aula que estamos acostumados.”

A gestão e aproveitamento do tempo foram outras competências citadas pelos estudantes como positivas com o ensino remoto, pois que fazem refletir sobre as dificuldades de locomoção nas cidades, o tempo "perdido" 
no deslocamento entre o trabalho e a IES, a lotação e más condições do transporte público, entre outros fatores pessoais que levam ao desgaste físico e mental, podendo resultar em dificuldades acadêmicas.

“Está sendo boa, pois consigo conciliar melhor com meu trabalho e tarefas de casa.”

"Prefiro a educação presencial, sem dúvidas. Mas reconheço diversas vantagens do ensino à distância. Na minha experiência pessoal, tenho tido muito mais tempo livre para os estudos, consigo me organizar e cumprir com meu planejamento semanal, dentro dos horários que considero melhores e com os intervalos necessários.”

Outros ainda relataram o fato de possuírem horas vagas na grade semanal de aulas, muitas vezes ficando longos períodos sem aula. As aulas remotas facilitaram nesse sentido, pois além de ser considerada mais cômoda permite que as aulas sejam gravadas:

“[...] a possibilidade do acesso às gravações ajuda muito no auto planejamento de estudos. No ensino presencial, as vezes tínhamos que nos deslocar de casa para termos apenas um tempo de aula o que era muito desgastante [...]"

A estimulação da construção de um conhecimento relacionado a qualidade dos materiais de estudo, liberdade de opinião sobre seus conhecimentos e autonomia nos estudos, são pontos positivos relacionados ao ensino remoto e que favorecem o crescimento intelectual e pessoal dos estudantes (SILVA et al, 2020).

Neste ínterim, fica claro que a emergência em se apresentar um novo formato de ensino/aprendizagem propiciou novas experiências para professores e estudantes. E ainda estimulou práticas voltadas à autonomia no processo ensino/aprendizagem, com o estudante como sujeito do processo.

\section{2 Influência do ambiente na experiência dos estudantes com o ensino remoto}

De acordo com os estudantes, as interferências externas são um fator prejudicial aos estudos. Segundo Santos (2020), a quarentena é mais difícil para alguns grupos sociais do que para outros, tornando-a limitadora e discriminatória para aqueles cujas condições socioeconômicas são menos favoráveis.

"Difícil, pois tenho duas crianças em casa e o ambiente não fica favorável aos estudos e sinto falta de aulas práticas para o melhor entendimento da matéria.”

"Estou com muita dificuldade para ter tempo para estudar, pois minha mãe trabalha e eu também preciso assistir aula com meu irmão mais novo e ajudar ele a fazer as tarefas.”

Outro ponto a ser considerado é o fato do ambiente caseiro permitir maior acomodação por parte de alguns estudantes, não favorecendo assim a atenção e dedicação necessárias aos estudos.

“[...] infelizmente, as distrações externas e a comodidade de estar em casa acabaram prejudicando alguns momentos que poderiam ter sido de maior e melhor dedicação.”

"O ambiente caseiro impede minha concentração nos estudos. Por mais que meus familiares entendam a necessidade, é difícil achar um lugar silencioso que me faça concentrar. O ambiente universitário é propício aos estudos. O caseiro tem certo grau de acomodação[...].” 
A tecnologia também é um fator externo que merece atenção, pois o acesso à internet insuficiente e de má cobertura influencia na assiduidade dos estudantes aos estudos. Segundo Vercelli (2020), as maiores dificuldades encontradas em seu estudo sobre ensino remoto, foram relacionadas ao uso da tecnologia e acesso inadequado à internet.

"Está sendo difícil por diversos fatores ligado a tecnologia, tanto da minha casa quanto as dos professores.”

“Ruim, pois minha internet não permite acompanhar.”

“[...] em determinados momentos, devido a conexão da internet e influências externas, dificulta-se um pouco.”

Embora as tecnologias tenham permitido novas possibilidades de aprendizagem, pesquisa e organização das instituições, através de atividades mais ativas e que estimulam a autonomia dos estudantes, os conselhos de diversos cursos da saúde referem a necessidade da presença do professor nos processos de aprendizagem. Dessa forma, esse novo modelo de ensino deve ser extremamente discutido visto que a o ensino remoto pode afastar os alunos das situações reais e comprometer sua atuação futura no mundo do trabalho (NETO, 2020; TORRES et al, 2020).

A quantidade de atividades advindas do ensino remoto, senão equilibradas pelos professores em seu planejamento, podem causar desestímulo para os estudantes. Portanto, não podem deixar de serem consideradas: a individualidade de cada estudante e sua relação com o conhecimento (BARBOSA, VIEGAS e BATISTA, 2020).

\begin{abstract}
“A plataforma adotada pela faculdade é boa, mas o número de aulas estava muito alto e estou com dificuldade de adaptação[...] São passadas muitas tarefas considerando que os questionários também estão sendo utilizados. Tenho dificuldade de manter a matéria em dia principalmente por precisar entregar tantos trabalhos e ainda responder a prova online."
\end{abstract}

“[...] As aulas que presenciais já eram maçantes tornam-se ainda mais via remota, além da quantidade de tarefa que nunca fora cobrado antes dos alunos [...].”

Vivenciar disciplinas online divide as opiniões dos alunos, existem aqueles que acham que se aprende mais quando a aprendizagem se torna autônoma e há aqueles que acreditam que não se aprende assim e que estar presente no momento de aprender é essencial. Estudos relatam que a maior dificuldade dos alunos está no tempo e organização pessoal, sendo isso a chave para o sucesso neste momento. Um dos pontos positivos encontrado nas aulas remotas é a flexibilidade do aluno poder estudar no momento que lhe for mais viável já que a plataforma permite a gravação das aulas (LUZEIRO et al, 2014; SILVA et al, 2020).

É importante ressaltar que esta atividade momentânea e das disciplinas estritamente teóricas não deve de forma alguma substituir aulas práticas na formação de cursos da área de saúde. Pois, a formação em saúde não se limita a oferecer somente conteúdo teórico, porque "exige o desenvolvimento de habilidades técnicas, clínicas e laboratoriais que não são passíveis de aquisição na modalidade EAD, sem o contato direto com o ser humano, visto tratar-se de componentes da formação que se adquirem nas práticas inter-relacionais” (COFEN, 2019; CNS, 2020).

Torna-se necessário o apoio da família e da sociedade para o desenvolvimento das atividades remotas durante a formação dos estudantes em tempos de pandemia. É mister a reflexão de que algumas nuances desse tempo pandêmico permanecerão no futuro, entretanto o ensino presencial estará, tão logo quando possível, permeando as atividades de ensino em nossa sociedade. 


\section{CONCLUSÃO}

Conclui-se que os estudantes passaram pelo período de adaptação às aulas remotas tendo diferentes experiências e que puderam apontar tantos pontos positivos, como negativos deste novo processo. Torna-se necessário investir em estratégias para minimizar os pontos negativos modificáveis, e propiciar experiências assertivas para os estudantes em formação.

Os desafios ora propostos devem servir como estímulo para novas práticas educacionais híbridas, sem perder de vista o caráter formativo dos estudantes da área de saúde, que irão se confrontar durante a realidade dos serviços com demandas de natureza tecnológica, mas principalmente com demandas humanistas, éticas e sociais que dependem de interação com seus pares durante a formação acadêmica.

\section{REFERÊNCIAS}

BARBOSA, A.M.; VIEGAS, M.A.S.; BATISTA, R.L.N.F.F. Aulas presenciais em tempos de pandemia: relatos de experiências de professores do nível superior sobre as aulas remotas. Rev.Augustus. Jul/Out; v.25, n. 51, p.255-280, 2020. Disponível em: https://revistas.unisuam.edu.br/index.php/revistaaugustus/article/view/565 Acesso em: 02 jul 2020.

BRASILa. Ministério da Saúde. Secretária de Vigilância em Saúde. Boletim epidemiológico n. 5. Doença pelo Coronavirus 2019. Brasília: Ministério da Saúde, 2020. Disponível em: https://www.saude.gov.br/images/ pdf/2020/marco/24/03--ERRATA---Boletim-Epidemiologico-05.pdf Acesso em: 02 jul 2020.

BRASILb. Decreto Legislativo $\mathrm{n}^{\circ}$ 6, de 2020 Reconhece, para os fins do art. 65 da Lei Complementar $\mathbf{n}^{\circ}$ 101, de 4 de maio de 2000, a ocorrência do estado de calamidade pública, nos termos da solicitação do Presidente da República. Disponível em: http://www.planalto.gov.br/ccivil_03/portaria/DLG6-2020.htm. Acesso em 05 jun 2020.

BRASILc. Ministério da Educação. Portaria no 343, de 17 de março de 2020. Dispõe sobre a substituição das aulas presenciais por aulas em meios digitais enquanto durar a situação de pandemia do Novo Coronavírus - COVID-19. Disponível em: http://www.in.gov.br/en/web/dou/-/portaria-n-343-de-17-de-marcode-2020-248564376. Acesso em: 07 jul 2020.

CAVALCANTI, R.L.S. Uma experiência pioneira em ensino de ciências da saúde via internet na Marinha do Brasil. Revista Práxis. V.9, n.17, 2017. Disponível em: http://revistas.unifoa.edu.br/index.php/praxis/article/view/707/1178

COFEN. Conselho Federal de Enfermagem. MPF recomenda suspensão de novos cursos EaD em Saúde. COFEN. 2019. Disponível em: http://www.cofen.gov.br/mpf-recomenda-suspensao-de-novos-cursos-ead-emsaude_74410.html. Acesso em: 02 jul 2020.

CONSELHO NACIONAL DE SAÚDE. Resolução nº 048, de 01 de Julho de 2020. Recomenda ao Ministério da Educação, que observe o Parecer Técnico n ${ }^{0}$ 162/2020, no que diz respeito a estágios e práticas na área da saúde durante a pandemia de Covid-19. Conselho Nacional de Saúde. 2020. Disponível em: http://conselho. saude.gov.br/recomendacoes-cns/1250-recomendacao-n-048-de-01-de-julho-de-2020 Acesso em: 07 jul 2020

COSTA, R. et al. Ensino de enfermagem em tempos de Covid-19: como se reinventar nesse contexto? Texto contexto - enferm. Jul, v.29, 2020. Disponível em: http://www.scielo.br/scielo.php?script=sci_ arttext\&pid=S0104-07072020000100102\&lng=en\&nrm=iso. Acesso em 08 jul 2020. 
FERNANDES, W.S. et al. Educação a distância: principais aspectos positivos e negativos. Rev. Bra. Edu. Saúde. out-dez, v. 8, n. 4, p. 41-47, 2018. Disponível em: https://www.gvaa.com.br/revista/index.php/REBES/ article/view/6095. Acesso em: 09 jul 2020.

LUNA, A.A. et al. Qualidade de vida dos estudantes universitários. $8^{\circ}$ Seminário de Iniciação Científica. Ago, 2017. Disponível em: https://repositorio.pgsskroton.com/bitstream/123456789/4537/1/QUALIDADE\%20 DE\%20VIDA\%20DOS\%20ESTUDANTES\%20UNIVERSITÁRIOS\%20-\%20UPAR.pdf.

LUZEIRO, C; SANINO, G.E.C; AMARAL, J.G. Percepção dos alunos do curso de graduação em enfermagem na modalidade presencial sobre as disciplinas cursadas online. 2014. Disponível em: http://www.abed.org. br/hotsite/20-ciaed/pt/anais/pdf/79.pdf. Acesso em: 09 de jul 2020.

NETO, J.M.F.A. Sobre ensino, aprendizagem e a sociedade da tecnologia: por que se refletir em tempo de pandemia?. Prospectus, v. 2, n. 1, p. 28-38, 2020. Disponível em: https://prospectus.fatecitapira.edu.br/index. php/pgt/article/view/32. Acesso em: 09 de jul 2020.

SANTOS. B.S. A cruel pedagogia do vírus. Coimbra: Almedina, 2020. Acesso em 07 jul 2020.

SANTOS JUNIOR, V.B.S; MONTEIRO, J.C.S. Educação e Covid-19: As tecnologias digitais mediando a aprendizagem em tempos de pandemia. Revista Encantar. jan/dez; v.2, p.01-15, 2020. Disponível em: http:// www.revistas.uneb.br/index.php/encantar/article/view/8583. Acesso em: 09 de jul 2020

SILVA, M. A.L. et al. A avaliação do ensino semipresencial sob à ótica do acadêmico de enfermagem. Revista Eletrônica Acervo Saúde, n. 47, p. 3080-3080, 2020. Disponível em: https://acervomais.com.br/index.php/ saude/article/view/3080. Acesso em: 09 jul 2020.

SILVA, L.C. et al. Percepções de estudantes de enfermagem sobre a educação a distância. Cienc. enferm. vol.22, n.2. 2016. Disponível em: https://scielo.conicyt.cl/pdf/cienf/v22n2/art_10.pdf Acesso em: 08 jul 2020.

TORRES, A.C.M; ALVES, L.R.G; DA COSTA, A.C.N. Educação e Saúde: reflexões sobre o contexto universitário em tempos de COVID-19. Disponível em: https:/preprints.scielo.org/index.php/scielo/preprint/ view/640. Acesso em: 09 jul 2020.

VERCELLI, L.C.A. Aulas remotas em tempos de Covid-19: a percepção de discentes de um programa de mestrado profissional em educação. Revista @mbiente educação. Mai/Ago; v. 13, n. 2, p. 47-60, 2020. Disponível em: http://publicacoes.unicid.edu.br/index.php/ambienteeducacao/article/view/932. Acesso em: 07 jul 2020. 